\title{
Versiones de lo afro en Antioquia: una aproximación a las estéticas musicales de Girardota*
}

AFRO VERSIONS IN ANTIOQUIA: A MUSICAL AESTHETICS APPROACH OF GIRARDOTA

VERSÕES DO AFRO EM ANTIOQUIA: UMA ABORDAGEM ÁS ESTÉTICAS MUSICAIS EM GIRARDOTA

\section{América Larraín González** Pedro José Madrid Garcés***}

Cuadernos de Música, Artes Visuales y Artes Escénicas

/ Volumen 13 - Número 1 / Enero - Junio de 2018

/ ISSN 1794-6670/ Bogotá, D.C., Colombia / pp. 265-280

Fecha de recepción: 12 de mayo de 2016

Fecha de aceptación: 12 de enero de 2017

Disponible en línea: 6 de diciembre de 2017

doi:10.11144/javeriana.mavae13-1.vaea

Artículo de investigación. Es producto de la investigación, La danza y el sainete: una aproximación a las manifestaciones culturales afro en el municipio de Girardota (Antioquia), financiada por la Vicerrectoría de Investigación de la Universidad Nacional sede Medellín, dentro de la convocatoria de proyectos para el fortalecimiento de la investigación, la creación y la innovación en posgrados de la Universidad Nacional de Colombia 2013-2015.

Antropóloga por la Universidad Nacional de Colombia, especialista en Gestión Cultural y Comunicación por la Facultad Latinoamericana de Ciencias Sociales, magíster en Antropología Social por la Universidade Federal de Santa Catarina y doctora en Antropología Social por la misma universidad. Profesora asistente del Departamento de Estudios Filosóficos y Culturales de la Universidad Nacional de Colombia sede Medellín. 


\section{Resumen}

El objetivo del presente escrito es ofrecer una reflexión sobre las manifestaciones artísticas de una comunidad afrodescendiente en el departamento colombiano de Antioquia. A partir de un trabajo de campo interdisciplinar, exploramos con especial atención la música de cuerda pulsada que ha permitido visibilizar en el ámbito regional, nacional e internacional, a intérpretes y compositores de esta comunidad. La contribución de la investigación consignada en este texto es explorar el papel preponderante de estas manifestaciones en la afirmación étnica del grupo, donde a diferencia de otras poblaciones afro del continente, no existe una tradición musical de percusión. Esta investigación concluye que el grupo estudiado afirma su identidad a partir de la interpretación de música y otras prácticas que son asociadas a un origen ibérico, pero que en el contexto local han sido apropiadas e incorporadas como parte de su legado y tradiciones, tal como ocurre entre otros pocos grupos del país.

Palabras claves: música afrocolombiana; etnicidad; Girardota; Antioquia

\section{Abstract}

This paper offers an ethnographic approach to the artistic manifestations of the Afro-descendant community of the San Andrés village; located in the municipality of Girardota - Antioquia in northwestern Colombia. Particular attention is given to pulsed string music that has made it possible for performers and composers to make this community visible at regional, national and international levels. The text explores various aspects of this aesthetic manifestation, including its place in the production and creation of other artistic practices such as dances and the sainete; which in recent years, have had a predominant role in the ethnic affirmation of this community. This community differs from other afro groups of the continent, since there is no musical tradition of percussion, and the Afro-descendant community affirms its identity from the interpretation of string music, dance or theater of spanish origin.

Keywords: afro colombian music; ethnicity

\section{Resumo}

O presente escrito oferece uma aproximação etnográfica às manifestações artísticas da comunidade afrodescendente da localidade de San Andrés, no município de Girardota-Antioquia, noroeste colombiano. Aqui se tratara particularmente a música de corda pulsada que tem permitido visibilizar a nível regional, nacional e internacional, a intérpretes e compositores de dita comunidade. O texto explora diversos aspectos desta manifestação estética, dentre os quais seu lugar na produção e criação de outras práticas artísticas tais como as danças e o sainete, que nos últimos anos, têm tido um papel central na afirmação étnica de dita comunidade, onde de forma diferente a outros grupos afro do continente, não existe uma tradição musical de percussão, e a população de ascendência africana, bem como outras poucas comunidades no país, afirma sua identidade a partir da interpretação de músicas de corda, dança ou teatro de origem espanhola.

Palavras chave: música afro-colombiana; etnicidade; Girardota; Antioquia

Girardota; Antioquia 


\section{INTRODUCCIÓN}

Este artículo fue elaborado dentro del proyecto de investigación La danza y el sainete: una aproximación a las manifestaciones culturales afro en el municipio de Girardota (Antioquia). ${ }^{1}$ En esta investigación, indagamos sobre la dimensión política de la cultura en el lugar referido, describiendo las interacciones y las dinámicas sociales propias de ciertas manifestaciones artísticas, que para el caso referido han tenido una gran importancia en las reivindicaciones étnicas de la comunidad rural de San Andrés.

En este artículo, nos concentraremos en los aspectos que tienen que ver con las estéticas musicales, convencidos de la importancia que tiene una reflexión sobre este tema desde las ciencias sociales, por tratarse de un campo del conocimiento que busca comprender las características de los diferentes modos de socialización humana en diálogo con sus dimensiones históricas, económicas y políticas, entre otras. Nos interesa aquí, de forma particular, mostrar cómo a través de la música los individuos y las comunidades construyen sentidos y generan procesos de identificación que dan corpus a su existencia social.

Son muchos los abordajes a partir de los cuales se ha pensado la música: históricos, sociológicos, políticos, estéticos, técnicos, etc. En el ámbito de las ciencias sociales y las humanidades, la música ha revelado ser un espacio importante de reflexión sobre los propios grupos que la producen y consumen, lo cual ha permitido profundizar en las dimensiones sociales, históricas y políticas que constituyen el entorno en que surge y se consolida como manifestación estética. Este es el asunto que exploramos aquí, a partir del caso particular de la agrupación Aires del Campo, conjunto de cuerdas pulsadas que interpreta ritmos pertenecientes a los géneros andinos vistos comúnmente como "música colombiana", entre los que se encuentran bambucos y pasillos.

Para comenzar, es importante resaltar que, paradójicamente, ha sido a través de una estética reconocida en la historia nacional como parte del proyecto de blanqueamiento oficial que una comunidad campesina se reivindica y reafirma su herencia negro-africana (Wade 2002). Es importante resaltar también que el caso girardotano no es excepción nacional, pues, en el contexto colombiano, existen otros grupos de ascendencia africana que no comparten el imaginario de lo afro asociado, exclusivamente, a una musicalidad de percusión, y que, por el contrario, interpretan instrumentos de cuerdas, como los raizales insulares en San Andrés y Providencia y las comunidades negras del norte del Cauca, quienes con sus violines han obtenido también recientemente visibilidad en el escenario nacional, a través del Festival Petronio Álvarez, uno de los más importantes certámenes musicales del país, cuyo caso ha sido explorado a fondo en el trabajo de autoras como Muñoz (2012) y en documentales que registran la interpretación del instrumento y todas las dinámicas asociadas a ella.

Para el caso que nos ocupa aquí, partimos considerando el contexto estudiado como un ejemplo de las diversas interacciones ocurridas en la historia cultural de la región, donde se configuraron identidades que dan cuenta de las formas económicas de producción coloniales, al mismo tiempo que revelan las maneras a través de las cuales se dio y se continúa dando la resistencia cultural: mediante la incorporación, la transformación y la reproducción de distintas prácticas estéticas y artísticas en la comunidad, que, si bien tienen como marco referencial un pasado colonial, se constituyen en estrategias de reivindicación étnica afro. 
En ese sentido, nuestro foco de estudio es un caso que no llena estadios ni cierra avenidas de grandes ciudades, pero que es fundamental como parte integrante de un tejido social rural que es clave en el proceso de reformulación identitaria de comunidades negras en el contexto de un Estado que se declara multicultural, como el colombiano. La importancia de la producción musical en la comunidad mencionada tiene impacto más allá de la música por sí misma, pues se trata del medio y la posibilidad de existencia de otras manifestaciones artísticas, como la danza y el sainete, que configuran el repertorio cultural de la comunidad afrodescendiente en cuestión.

\section{LOS NEGROS EN EL VALLE DE ABURRÁ}

En los Andes noroccidentales colombianos, en el departamento de Antioquia, subregión norte del valle de Aburrá, se encuentra ubicado en la margen oriental del río Medellín, el municipio de Girardota. Esta región fue conocida desde finales del siglo XVI como las Tierras del Río Abajo siendo su primer propietario el gobernador don Gaspar de Rodas. Para 1620, Girardota es fundada, colonos llegados de la ciudad de Antioquia levantaron el primer caserío en el paraje denominado San Diego (López, Rendón y Palacio, 2006). Este proceso de colonización fue acompañado de una evolución de la propiedad y un proceso de migración hacia esa zona, en la que la limitación de recursos obligaba a los colonos a implementar actividades distintas de la búsqueda de oro, como la siembra de caña de azúcar y la cría de ganado con el uso de mano de obra esclava (Correa 2002).

Durante el proceso de ocupación del territorio, fueron cuatro los grandes núcleos poblacionales: San Diego, San Esteban, El Totumo y San Andrés. Este último se caracterizó por tener un grupo poblacional diferente de los demás asentamientos del municipio. Por ser un territorio montañoso que permitía a los esclavos cimarrones escapar de las haciendas localizadas al borde de las vegas del río, fue allí donde se concentró la mayor parte de la población negra (Meneses 2006).

La vereda de San Andrés está ubicada en la margen izquierda del río Medellín, tres kilómetros al nororiente de la cabecera municipal. Según Correa (2002), se trata de una vereda sin igual por la tradición cultural de sus antepasados negros, quienes fueron traídos al territorio para suplir la mano de obra indígena. En el registro del sistema hacendario del municipio de Girardota, consta que llegaron 103 en 1665, procedentes del continente africano, en especial de Guinea, Angola, Congo y Cabo Verde (Correa 2002).

"La hacienda como núcleo de producción fue importante para criollos, mestizos, mulatos y esclavos, pues esta configuró un centro de actividades no solo materiales como agricultura, ganadería y trapiches, sino también culturales y artísticas como artesanías y bailes" (López, Rendón y Palacio 2006, 7). Así fue como la población negra, una vez manumitida (Pita 2014), se quedó en el territorio donde se habían establecido desde la Colonia, territorio conocido, en el cual lazos de sociabilidad constituyeron lo que hoy reivindican como que conoce y da forma al territorio ancestral de San Andrés (Corantioquia 2011a, 44). 


\section{MANIFESTACIONES ARTÍSTICAS EN LA VEREDA DE SAN ANDRÉS}

Caracterizada por un fuerte arraigo religioso, consecuencia del catolicismo instituido, la vereda tuvo en las festividades y celebraciones sagradas uno de los principales palcos para las intervenciones artísticas. La música, por ejemplo, se tocaba y bailaba en romerías, primeras comuniones y bautizos. Las primeras que ya han desaparecido cobraron gran importancia como reuniones comunitarias, en las cuales era clave la figura del sacerdote, pues era este quien las autorizaba e instalaba (López, Rendón y Palacio 2006, 6).

Por otra parte, en el último siglo, gracias a la diversificación de la economía local con la implementación de actividades tales como la agricultura y la construcción, pero particularmente con la obra y puesta en marcha del ferrocarril de Antioquia y el establecimiento de la Estación San Andrés, localizado en la parte baja de la vereda, se dio un importante contacto con pobladores de diversas regiones y así se favoreció el contacto con otras expresiones culturales, particularmente musicales, que entraron a hacer parte del repertorio de las tradiciones de San Andrés (Foronda 2002, 26).

Ya durante la Colonia fue la fiesta el escenario de encuentro por excelencia que en la vereda de San Andrés se integran mestizos, afrodescendientes y criollos. Estas fiestas, denominadas bailes bravos o bailes de calle fueron el espacio donde se gestaron manifestaciones artísticas, como la música, la danza, las trovas, la poesía y, en especial, los sainetes.

El término baile bravo estaba designado entonces en un fenómeno social-cultural que congregaba varios elementos sociales y que fue común en varias localidades del Departamento... en el caso particular de San Andrés tiene una significación social étnica (afirmación como grupo humano negro), política (en cuanto expresión de intereses propios de un grupo humano) y ritual comunitaria, nexos con expresiones mágico-religiosas (afinaciones o temples especiales bajo los cuales adquiría características mágicas: personalización del diablo en las diferentes interpretaciones artísticas). (López, Rendón y Palacio 2006, 35)

Es muy probable que el proceso de apropiación y transformación de los géneros musicales y dancísticos de origen europeo haya tenido lugar cuando la población afrodescendiente curioseaba las fiestas que realizaban sus patrones a puerta cerrada, extrayendo de allí partes de la música, la danza y el sainete, para luego interpretarlas en sus propias fiestas, adecuando las diferentes expresiones artísticas a la vida cotidiana de la vereda y convirtiéndolas en prácticas significantes para la comunidad (Corantioquia 2011b).

La población afro se apropió de elementos artísticos disponibles en el contexto de la época, mediante la observación de bailes y teatro español, modificándolos y convirtiéndolos en escenarios para la fiesta y el disfrute de sus comunidades (Wabgou 2012). Un aspecto llamativo en relación con esta apropiación es que tuvo desde sus orígenes un carácter de ridiculización de las figuras autoritarias de la época, siendo también un espacio para la incorporación de acontecimientos triviales de la comunidad, mediante un ejercicio de creatividad y articulación de los distintos elementos estéticos que tenían a disposición y que les eran permitidos, tales como la música, la danza, el teatro y la declamación. 
Es pertinente mencionar aquí que las categorías y denominaciones alrededor de las prácticas musicales populares, en general, son complejas y cuentan con notables discusiones. Tal es el caso del enfoque de los géneros musicales que autoras como Ochoa (2003) o Guerrero (2012) desarrollan a partir de interesantes reflexiones sobre las formas de clasificación de las prácticas musicales, sus límites, alcances y su importancia para la comprensión de los escenarios sociales donde se inscriben.

Por otra parte, Piedade (2007) señala que uno de los puntos más importantes de los estudios de música popular es la descripción y el análisis de los géneros, que deben ser vistos como manifestaciones del mundo empírico y que, como en el mundo literario, constantemente se transforman. Por ese motivo, el autor exhorta el uso de una perspectiva que, siguiendo a Bakhtin (1986), estudie los géneros musicales como discursos.

Dicho esto, resaltamos que en nuestra reflexión al hablar de música colombiana, música andina o danza y sainete no nos estamos refiriendo a un conjunto de prácticas estáticas y estrictamente definidas en términos técnicos o históricos, sino que lo hacemos a partir del uso que de estas clasificaciones hacen sus practicantes, sin desconocer que la construcción de cada una de ellas conlleva una carga ideológica y política que se ha transformado en el tiempo, haciendo visibles e invisibles, simultáneamente, a determinados actores.

En ese sentido, trabajos como el de Wade (2002) o el de Blanco (2009) exponen de forma magistral la transformación del imaginario de un país, cuyo referente principal fue durante siglos el interior andino, que en el último medio siglo desplazó su eje hacia los litorales tras lo cual se convirtió en una nación que tiene en el Caribe una importante reserva de imágenes constitutivas de la idea predominante de colombianidad.

En resumen, para el caso que nos atañe aquí, vemos que las celebraciones religiosas, las fiestas de los patrones y las influencias y referentes culturales facilitados por la instalación del ferrocarril crearon una coyuntura propicia para la consolidación de la danza y el sainete, manifestaciones artísticas de la vereda de San Andrés que conocemos hoy en día, y que tienen en la música andina de cuerdas pulsadas su eje y condición indiscutible de realización y existencia.

Por otra parte, es pertinente señalar, en relación con la condición étnica de la población estudiada, que entrado el siglo XX, y a pesar de la abolición de la esclavitud en el contexto nacional colombiano, existían en la región fuertes tensiones sociales y políticas entre la población considerada blanca-mestiza y los afrodescendientes. De ello da cuenta la tradición oral: "Ellos [los negros] no iban mucho al pueblo [...] porque era que la gente de las partes urbanas no los estimaban mucho, entonces ellos se mantenían retirados... aquí en San Andrés" (Cadavid, citado en López, Rendón y Palacio 2006, 3).

Como resultado del aislamiento inducido por las élites criollas asentadas en el casco municipal, la comunidad afrodescendiente generó procesos de especialización de sus manifestaciones artísticas que proliferaron a través de los encuentros de fin de semana, grupos de danza, música de cuerda y saineteros. Ellos ensayaban los sábados en las tardes, luego de efectuar su jornada laboral, para refinar, componer y mejorar sus interpretaciones en los bailes de calle. Asimismo, era en este tipo de encuentros en los que se hablaba de los problemas de la vereda y de las necesidades de la comunidad, donde se programaban convites para la construcción y reparación de vías y casas, al igual que trabajo conjunto en producciones, en especial de caña de azúcar y ganadería.

En Girardota, la proliferación de manifestaciones artísticas fue notable, pues, además de la realización de la danza y el sainete entre la comunidad afrodescendiente de la vereda de San Andrés, también se consolidaron expresiones tales como las trovas, la declamación de poesía 
autóctona, la composición musical, los alabados, ${ }^{2}$ las novenas, las veladas y los cantos fúnebres, entre otros. Sin embargo, es pertinente mencionar que, en los recientes procesos de institucionalización y patrimonialización de las festividades municipales, solo se reconocieron y fomentaron la danza y el sainete.

La música de cuerdas pulsadas, junto con la danza y el sainete, ocurren de forma simultánea y son interdependientes en algunas circunstancias: para que exista el sainete, es requisito fundamental la música y la danza; para la danza, es indispensable la música. La música es la única que puede ser interpretada de forma independiente de los demás elementos que componen el mencionado conjunto estético.

A efectos de reconocimiento y visibilidad de la comunidad de San Andrés como grupo afrodescendiente, estos tres elementos (música, danza y sainete) han sido resignificados, pues no es a partir de sus referentes "originales" que son evocados, sino a partir de su apropiación y de la transformación que esta comunidad ha hecho a lo largo de su historia, lo cual les ha permitido construir sentidos e identidad más allá de su caracterización física, mediante formas de expresarse a través del arte, en un territorio que reconocen como propio.

En esa medida, no se trata del color de piel como elemento que determine la carga cultural o las formas de socialización de las que puede disponer un ser humano o una colectividad, sino, por el contrario, se trata de la identificación y el sentido de adscripción que surge de las complejas tramas de la historia y de la vida social.

\section{LA MÚSICA: AIRES DEL CAMPO}

En el ámbito de la etnomusicología, se exalta la potencialidad de la música como medio que permite auscultar los diversos sentidos que los grupos humanos dan a su existencia, tanto en contextos tradicionales como modernos, rurales o urbanos (Merriam 1964; Blacking 1967; Shepherd 1991; Menezes Bastos 2013). Por ello, el estudio de las músicas regionales y locales es un camino privilegiado para acceder a información sobre aspectos históricos, sociales, políticos y simbólicos, fundamentales para una comprensión más amplia de las diferentes dinámicas y transformaciones de las sociedades y los grupos humanos.

Si bien la música constituye un saber ancestral en la vereda de San Andrés, los instrumentos y formatos musicales han sido diversos a lo largo de la historia de esta tradición hasta el punto de poder decir que la conformación actual de guitarra, tiple, bandola, guacharaca y voz es relativamente "nueva" (López, Rendón y Palacio 2006, 9).

Anteriormente la vihuela ${ }^{3}$ era el instrumento utilizado en la vereda para efectuar las fiestas. En ellas se interpretaba este instrumento acompañado de cantos para animar y divertir a las personas. En el caso de agrupaciones musicales de la vereda, la diversificación de los instrumentos de cuerda se da a través de dos antiguos pobladores de la región: Pedro Santiago Cadavid y Clemente Saldarriaga, vihuelistas y grandes representantes de la música en la vereda, según la tradición oral.

Fue allí que surgió la agrupación musical Aires del Campo, que a su vez tuvo como antecesora el grupo Brisas del Norte y los Cadavices, intérpretes de músicas que los pobladores locales denominan autóctonas. Esta asociación primaria entre los Cadavid y los Saldarriaga abrió paso al proceso de transmisión entre sus familiares con las prácticas sabatinas. Al respecto, Manuel Cadavid integrante de Aires del Campo indica: "Recuerdo que mi bisabuelo tocaba vihuela, mi abuelo tocaba tiple, mi papá guitarra al igual que los tíos, este legado lo llevaban en la sangre y es por eso que es muy importante continuar con tan bella tradición" (Palacio 2014). 
En relación con la autoría u originalidad de la música de la vereda de San Andrés y sus diferentes versiones, no hay registro respecto de las composiciones, por lo cual se apela siempre al rótulo genérico de música andina colombiana. Dentro de esa gran clasificación, interpretan música parrandera campesina, pasillo fiestero y las tonalidades de baile bravo, ${ }^{4}$ que fueron y continúan siendo apropiadas y recompuestas por los habitantes de la vereda.

Frente a estas circunstancias se puede afirmar que "las diferentes realizaciones pueden ubicarse siempre en algún lugar de la línea de continuidad que existe entre los polos de la creación individual y del anonimato o la creación colectiva" (Domínguez 2011, 14). Por lo que, siguiendo la línea de la autora referida, se concluye que la condición de originalidad de la producción musical en la vereda de San Andrés ha cedido frente a la apropiación para el desarrollo de motivos populares y usos festivos en la comunidad.

Estas músicas son reconocidas por la comunidad pues dan cuenta de su entorno cotidiano, experiencias de vida, "géneros cortesanos que rememoran legados de la época de esclavitud; y repertorios populares que ilustran sobre la transformación del panorama sonoro ante la irrupción de los medios de comunicación y la urbanización creciente de la región" (López, Rendón y Palacio 2006, 12). Esta situación refleja la interacción cultural referida inicialmente y permite a la comunidad afrodescendiente definirse a través de sus manifestaciones artísticas y culturales.

Tal es el nivel de representatividad y significación que tiene la música de cuerda en la vereda de San Andrés que esta figura en las composiciones musicales mismas se erige como elemento central de lo que Menezes Bastos (2013) denomina una cadena intersemiótica, sirviendo de eje que articula la performance cultural como un todo, pues sin ella no sería posible la producción de las demás manifestaciones artísticas, ya que se trata del elemento primario que acompaña trovas, y prosas, al igual que da la pauta para las danzas y los sainetes. Esta música no se puede reemplazar con sonido digital, pues los mismos saineteros aducen que no sería autóctono el sainete y que esto dificultaría la presentación, además de ser de poco agrado para la comunidad, como lo refiere Gilberto Cañas (líder sainetero de la vereda).

Una de las particularidades de la música de la vereda de San Andrés es que difiere de aquello que ha sido reconocido en el imaginario nacional como música afro, pues no hay presencia de percusión y lo que prevalece, como ya fue señalado, son los géneros andinos de cuerdas pulsadas. "No todos los negros tocan tambor", es una afirmación de pobladores locales como Arnobia Foronda, quien además menciona que "esa pregunta nos la hacen mucho, sobre si nosotros tocamos tambor o tenemos percusión. Pues realmente los antiguos demás que lo tuvieron, pero eso se perdió" (El balcón 2014). En esta misma línea, Fred Danilo Palacio indica que "musicalmente hay en la vereda una herencia musical negra que no se asocia como es usual con tambores ni cantos africanos, sino con instrumentos de cuerdas y con melodías europeas. Esta herencia representa libertad y esclavitud" (El balcón 2014, 16). Este contexto evidencia la combinación cultural, junto con la apropiación (¿imposición?) y transformación de manifestaciones artísticas europeas, y posterior resignificación por parte de la comunidad negra con sus danzas y formas festivas.

El aprendizaje de la técnica de los instrumentos musicales en la vereda de San Andrés se ha efectuado mediante la observación de los mayores por parte de los más jóvenes. Al igual que en el sainete, memorizaban lo que podían observar por las ventanas o agujeros de las puertas de las fiestas de los blancos y luego lo acomodaban para sus fiestas, con especial dificultad, pues no se tenía acceso a los instrumentos musicales de las familias hacendarias, 
por lo cual estos mismos fabricaron sus propios instrumentos, que, según José Jesús Rojas Saldarriaga (hombre de más de 90 años, habitante desde su nacimiento de la vereda de San Andrés), "eran muy roncos, pues estos eran instrumentos hechizos, elaborados con maderas del territorio y piel de chivo o en su defecto nailon." Esta forma de aprendizaje y transmisión se mantiene bajo la observación constante y está sometida a un proceso de refinación auditiva en los ensayos personales diarios y en los grupales sabatinos.

Respecto del repertorio, este es de gran variedad, e incluye música denominada "tradicional" colombiana, como boleros, bambucos, merengues, pasillos, redova (originaria de la actual República Checa), al igual que las derivaciones musicales de los bailes bravos, clasificados y recuperados mediante audio por López, Rendón y Palacio (2006) de la siguiente manera: el gallinazo, vueltas de Girardota, vueltas remedianas, la panelita y la migajita, el destrós, el bunde, sainetiando y el shiotis.

Este listado da cuenta de las diversas influencias presentes en el actual repertorio de San Andrés, al igual que de la versatilidad de sus músicos para incorporar sonidos e instrumentos que no siguen estrictamente el canon musical de la región, por lo cual, en este punto, se sostiene que como en todo ejercicio de asimilación e interpretación de músicas tradicionales se puede hablar de creación (Domínguez 2011).

En relación con lo referido, Fred Danilo Palacio (investigador y músico profesional) expresa frente a la música de la vereda de San Andrés que "estas piezas de corte aristocrático se han tocado y bailado por décadas en San Andrés, y al lado de otros repertorios campesinos y festivos que sus antecesores llamaron bailes bravos, constituyen una genuina tradición cultural que enaltece la fiesta, la libertad y la picaresca popular" (en El balcón 2014, 11).

En el mismo sentido, Manuel Cadavid indica que "no solo tocamos música de la vereda, pues en las fiestas y cumpleaños en los que somos invitados se ofrece un amplio repertorio, ya que la gente a veces pide otra clase de música, por eso se incluye vallenato, bolero, porro y bambuco", situación que les permite acceder a un mayor público garantizándoles un ingreso alterno al de las labores semanales.

Independiente del provecho económico que se derive de las músicas, lo que llama la atención en esta agrupación musical es su tipología social, es decir, su profesión, dado que no son músicos de tiempo completo, ya que su contexto social y económico les han llevado, primero, a solventar sus necesidades básicas mediante labores agrícolas, agropecuarias y, en algunos casos, en las industrias locales. Además, dedican parte de su tiempo a desarrollar la tradición que aprendieron junto a sus ancestros a través de la observación-acción, con lo cual garantizan la permanencia de las prácticas culturales reconocidas en la vereda.

Como ya fue mencionado, es la agrupación Aires del Campo la encargada de interpretar el marco musical de las danzas y los sainetes, que representa no solo a Girardota y Antioquia, sino a Colombia en eventos musicales y festivales folclóricos internacionales. Una de las representaciones efectuadas, y que mayor orgullo da a los integrantes del grupo, es la participación en Washington en el Smithsonian Folklife Festival en 2011, donde el grupo en mención fue descrito como

\footnotetext{
"una agrupación de música tradicional de cuerdas del Eje Cafetero, que se distingue por tocar bandola y tiple, instrumentos tradicionales del área. Los miembros de la agrupación son primos que aprendieron a tocar enseñados por sus padres, sus tíos y su abuelo. El grupo interpreta música andina además de música paisa de la región" (figura 1).
} 
Los músicos de la agrupación Aires del Campo son herederos de una tradición familiar que históricamente ha estado vinculada con los diferentes grupos de saineteros y bailarines de San Andrés. "Cadavid, Arroyave, Peña, Cataño, Foronda, Puerta, Saldarriaga... son apellidos que han dado nombre y renombre a agrupaciones reconocidas en la vereda, en el municipio y en el ámbito nacional, en algunos casos" (López, Rendón y Palacio 2006, 7).

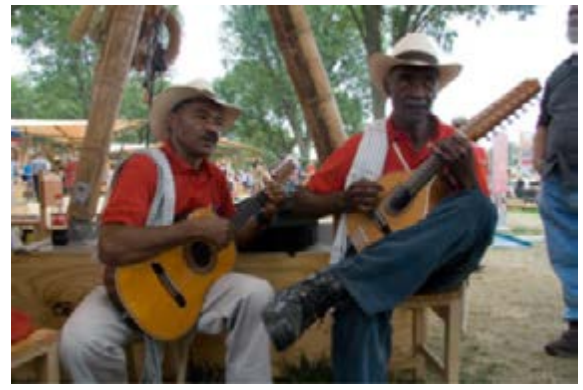

figura 1

Agrupación durante el Smithsonian Folklife Festival en 2011. Fuente: Smithsonian Folklife Festival (2011).

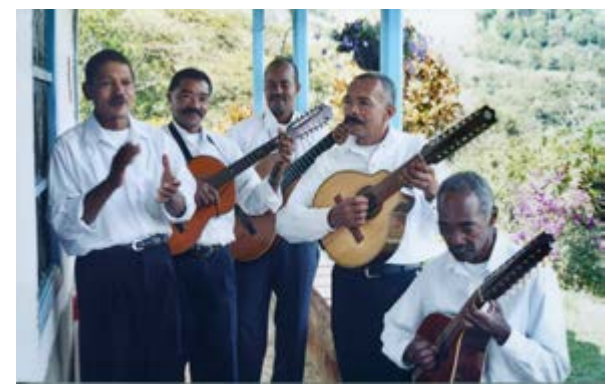

figura 2

Agrupación musical Aires del Campo. Fuente: Fotografía de los autores.

Los artistas que conformaron la base del grupo musical Aires del Campo son estos: Manuel José Cadavid Cataño, director, músico (tiple); Óscar de Jesús Cadavid Cataño, músico (primera bandola); Jorge Enrique Cadavid García, músico (guacharaca); y Fernán de Jesús Rojo Meneses, músico (guitarra).

- Dentro de las características identificadas en los procesos de aprendizaje y aproximación a prácticas musicales, los cinco integrantes de la agrupación Aires del Campo confluyen en:

- Los integrantes comienzan a incursionar en la música desde muy temprana edad, a través de la observación de los ensayos y las presentaciones festivas de sus parientes.

- Los artistas exploran diversos instrumentos musicales de cuerda, para luego concentrarse y especializarse en uno, en el que se afianzan y dedican sus ensayos desde la niñez.

- La influencia más próxima de los integrantes del grupo la adquieren de sus familiares, es especial de don Fidel y don Ernesto Cadavid, quienes transmitieron sus conocimientos musicales empíricos a sus sobrinos e hijos.

- Los integrantes se reconocen como músicos herederos de una tradición oral afrodescendiente, derivada de sus parientes y familiares afrodescendientes.

- El proceso de aprendizaje de la técnica musical se efectúa sin partituras o composiciones musicales escritas, técnica que se da con el refinamiento auditivo "a oído" y el ensayo semanal en conjunto.

- Dentro del repertorio musical del grupo hay gran diversidad de piezas sonoras, las cuales van desde música "andina", música para sainetes y música colombiana "tradicional" en general (figura 2). 
Por lo anterior, el rótulo bajo el cual ha sido fragmentada la música en Colombia es insuficiente para dar cuenta de la diversidad que albergan las diferentes prácticas musicales. Cuando se señala que Aires del Campo toca música "andina" o música "tradicional" colombiana, y a su vez reivindican esta práctica como parte de su herencia afro, pareciera haber una contradicción entre las ideas asociadas a la música andina y el imaginario de lo afro, impregnado de un carácter alegre y festivo. Con relación a esta reflexión,

el mito de la melancolía andina fue construido a partir de la apropiación y reelaboración de ciertos materiales musicales de origen africano e indígena por parte de una élite romántica, urbana y bohemia, interesada en crear una música nacional capaz de proyectar una imagen que estuviera en consonancia con la caracterización de Bogotá como una "Atenas suramericana." (Hernández 2014, 208)

Como se hace evidente aquí, es complejo el panorama de la clasificación de los géneros de la música en Colombia, en especial de aquellas músicas regionales o de grupos dispersos por todo el territorio del país, con particularidades históricas, como la de la comunidad asentada en la vereda de San Andrés. En términos generales, estas músicas han sido estudiadas con poco fondo desde las ciencias sociales y humanas, por lo cual resulta aún más difícil resolver el asunto de la música nacional entendiendo que,

si se acepta en principio que el sonido musical es un fenómeno significante, se debe aceptar también que los materiales sonoros están atravesados por relaciones de poder, pues inevitablemente participan en la permanente lucha de significados que constituye lo que entendemos por cultura. Al igual que cualquier otro modo de lenguaje, el sonido musical tiene la capacidad de favorecer unas representaciones de la realidad y cuestionar otras. (Hernández 2014, 11)

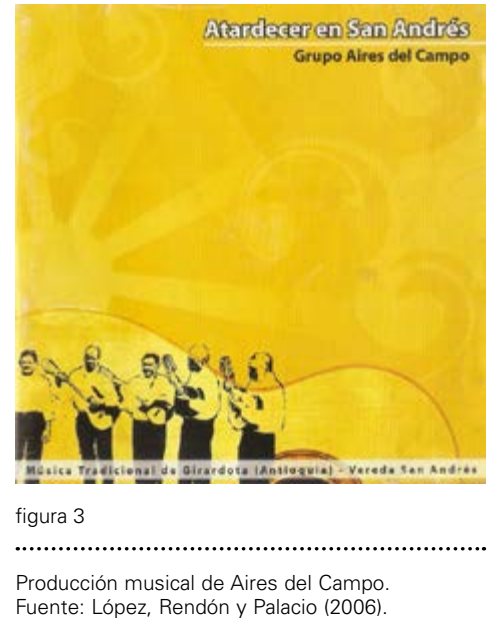

La tradición musical actual de Girardota y de la vereda de San Andrés remite a cantos y melodías que se han transmitido, de generación en generación, a versiones de músicos jóvenes y adultos que han aprendido al lado de sus parientes, muchos ya desaparecidos, remite a la influencia de diversos géneros en distintos momentos de la historia, a la danza, al sainete y, por esa vía de la teatralidad, a las dimensiones constitutivas de las relaciones sociales en un contexto que históricamente ha sido desigual y, en muchas ocasiones hostil, con la comunidad en cuestión.

En esta dinámica, de la cual puede hacerse memoria cerca de doscientos años atrás, participan músicas criollas o mestizas, experiencias de vida, géneros cortesanos que rememoran legados de la época de esclavitud, y repertorios populares que ilustran la transformación del panorama sonoro ante la irrupción de los medios de comunicación y la urbanización creciente de la región (López, Rendón y Palacio 2006) (figura 3). 


\section{MANIFESTACIONES ARTÍSTICAS Y ETNICIDAD}

Con la incursión del multiculturalismo en Colombia, y la visibilización de estas expresiones culturales en el ámbito nacional y departamental, la comunidad negra del sector tuvo una transformación vertiginosa de su identidad como colectivo, al erigirse como comunidad afrodescendiente con órganos directivos, por ejemplo el Consejo Comunitario, soportando su proceso de identificación en las manifestaciones artísticas descritas y no en el color de piel (Wainer 2000).

Desde 2000 se ha promovido en la vereda una etnización de la identidad (Castillo 2007) mediante expresiones artísticas, como la música, la danza y el sainete, que a su vez han promovido la gestión cultural de sus manifestaciones y formación de organizaciones formales para la administración de sus expresiones artísticas.

Aquí queda develada la importancia de formas tradicionales de transmisión de conocimiento artístico y musical, que obedece también a la inmaterialidad de estas manifestaciones artísticas, ya que son los cuerpos de los afros, moldeados y entrenados para la ejecución de música, danza y teatro, quienes se convierten en comunidad, para realizar los diversos encuentros culturales y manifestaciones artísticas. Esto debido a que las diferentes manifestaciones de este trinomio están atravesadas por lo que Merleau-Ponty (1993) define como corporeidad. Se puede tratar, por un lado, del refinamiento musical para interpretar las diferentes músicas de cuerda o del disciplinamiento del cuerpo para la expresión de las diferentes danzas, así como de la preparación para la exposición teatral mediante la introyección de los personajes del sainete y lo que pretenden evocar a través de estos roles.

Siguiendo a Bourdieu (1999), aquí vemos un cuerpo socializado ante una comunidad, que tiene como centro de producción y posibilidad artística la vereda de San Andrés. Esto permitirá, como se referirá más adelante, la reformulación de su identidad y producción de subjetividades en lo micro (Guattari y Rolnik 2013), junto con la construcción de un yo étnico que se expresa mediante las diferentes prácticas culturales afrodescendientes descritas.

Como se mencionó, la música permite en diversos contextos articular a la sociedad en espacios festivos mientras propicia un lugar para quebrar la rutina de la vida diaria. En el caso de la vereda de San Andrés, la música ha desempeñado el papel de encuentro entre las comunidades afro y criollas que habitan este territorio, lo cual ha generado compadrazgos y relaciones de vecindad. Desde principios del siglo XX, el acceso a medios tecnológicos para la producción musical era escaso, situación que alentó el aprendizaje e interpretación de instrumentos musicales en la vereda, lo cual permitió la presentación de las agrupaciones musicales en las fiestas de las distintas familias y afianzó las relaciones de la comunidad entre los diversos habitantes del territorio.

Estas presentaciones de fin de semana promovieron una manifestación artística fundamental en la vereda como es la danza. Esta actividad vincula no solo a las mujeres cabeza de familia, sino que abarca desde niños, niñas y adolescentes hasta los grupos de danza del adulto mayor. En su interpretación, y pese a las nuevas tecnologías y formatos musicales, los bailarines prefieren las formas tradicionales, pues según indican: "El grupo musical es muy importante, porque, si no está el grupo musical, no es autóctono el grupo de danzas" (entrevista con Enrique Cadavid, 23 de octubre de 2015). 
El trinomio artístico característico de la región (música, danza y sainete) ha sido visto con gran agrado por parte de las entidades estatales en el ámbito municipal y departamental, para asuntos de representatividad y participación en eventos culturales y festivos. Tanto es así que las fiestas de Girardota llevan por nombre las fiestas de la danza y el sainete (antiguamente fiestas de la guagua y el chagualo), que permite a las diferentes agrupaciones artísticas de la vereda, entre ellas Aires del Campo, presentarse al público girardotano en las programaciones culturales anuales.

Por otro lado, la música y las danzas de la vereda de San Andrés han sido convocadas a participar en festivales de danza en varias ocasiones para representar al departamento de Antioquia, lo cual ha visibilizado a los artistas de la vereda hasta tal punto que varios jóvenes ya pertenecen o pertenecieron al ballet folclórico de Antioquia.

Pese al panorama aparentemente alentador de exaltación del folclor local y de admiración a los artistas de la vereda, existe una preocupación que toca a todos los músicos, bailarines y saineteros: se trata de la incertidumbre frente a la eventual pérdida de sus tradiciones, en particular la música, dada la avanzada edad y el fallecimiento de varios de sus intérpretes. Frente a esto, en un intento por contrarrestar tal riesgo, la comunidad afrodescendiente, junto con entidades del sector público, ha promovido iniciativas para salvaguardar las expresiones más significantes del legado de sus ancestros (figura 4).

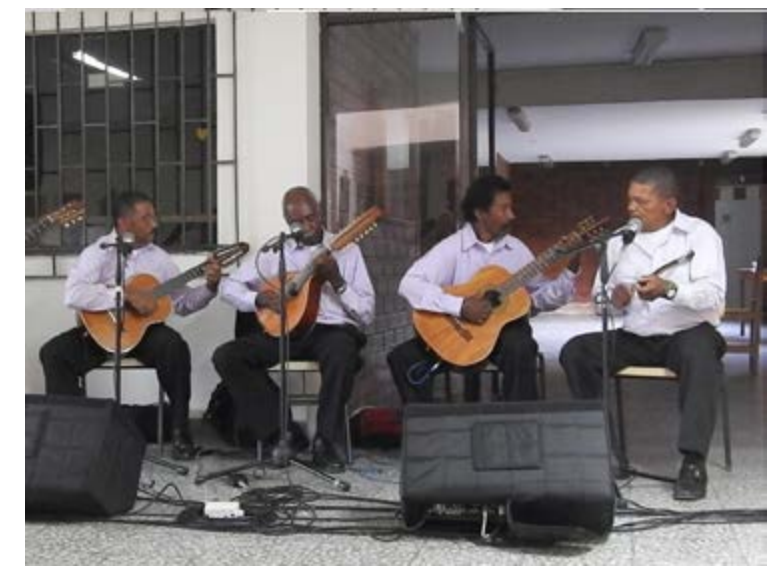

figura 4

Aires del Campo antes de acampamiento musical de sainetes. Fuente: Fotografía de los autores.

\section{REFLEXIONES FINALES}

Como se mencionó, la música de cuerda de la vereda girardotana de San Andrés y su agrupación más representativa, Aires del Campo, son la piedra angular que posibilita allí la integración de la comunidad negra a través de diversas expresiones artísticas, que a su vez les permiten hablar de autorreconocimiento y de identidad colectiva.

La música, en este tipo de comunidades, posibilita el despliegue de otras manifestaciones artísticas que representan la identidad y las formas de socialización autóctonas que fortalecen el significado de la fiesta en comunidades rurales, estructurando a su vez procesos de transmisión de conocimiento musical y artístico. 
El carácter festivo desempeña un papel crucial en las sociedades, ya que permite construir un escenario en el que se integran las diversas facciones sociales posibilitando la convivencia de las barreras de clase en pro del esparcimiento. En el caso de San Andrés, lo festivo es de tal importancia que sin su presencia las manifestaciones artísticas serían precarias y, en determinados casos, inexistentes, al igual que los lazos comunitarios y las relaciones de vecindad, según la tradición oral de la vereda. La música, en contextos como el de la vereda de San Andrés, permite articular y garantizar prácticas artísticas, como la danza y el sainete, y así estructurar el proceso de transmisión cultural.

Por otro lado, es fundamental señalar la dimensión política presente en las manifestaciones artísticas, como la música, y en el caso de San Andrés, las diversas expresiones folclóricas, como la danza, el sainete y los trovadores, ya que es a partir de estas manifestaciones que se reivindica la africanía y los remanentes coloniales de la esclavitud. "Existen, en efecto, muchos ejemplos de cómo la música ha sido usada a lo largo de la historia para favorecer los intereses específicos de personas o movimientos sociales" (Hernández 2014, 10). En San Andrés, esto es evidente en los procesos de reivindicación promulgados por sus líderes culturales y sociales.

Finalmente, la agrupación Aires del Campo, el grupo musical más representativo del escenario en cuestión, pese a la pérdida de varios de sus integrantes base, sigue tocando su música alrededor del mundo, animando sainetes y provocando bailes en la vereda. Aunque no llenan estadios, ni cierran grandes avenidas, resisten y continúan transmitiendo a la comunidad sus conocimientos musicales y culturales, al ser partícipes y protagonistas de las actividades artísticas colectivas que dotan de sentido y significado la vida de la población afrodescendiente de la vereda de San Andrés.

\section{NOTAS}

1. Universidad Nacional de Colombia sede Medellín.

${ }^{2}$ Según Arnobia Foronda (entrevista, 23 de octubre de 2015), esta manifestación artística consistía en que las mujeres rellenaban calabazas con maíz, para acompañar con el sonido de este instrumento versos en los que se iban contestando unas a otras. Se efectuaban estos cantos cuando nacía o moría un niño.

${ }^{3}$ Si bien se conoce con el nombre vihuela el instrumento español de cuerdas pulsadas del siglo XVI, similar al popular laúd, para el caso que nos ocupa aquí se trata de una de las muchas transformaciones que sufrió este en el ámbito latinoamericano. A pesar de conservar el nombre de vihuela, su construcción y usos varían mucho en distintos contextos.

${ }^{4}$ Según los pobladores locales, eran llamados bravos, ya que requerían gran energía y vitalidad para efectuar las danzas y sus coreografías. 


\section{REFERENCIAS}

Bakhtin, Mikhail. (1986). "The problem of speech genres". En Speech genres and other late essays, editado por Caryl Emerson y Michael Holquist, 60-102. Austin: University of Texas Press.

Blacking, John. 1967. How musical is man? Seattle: University of Washington Press.

Blanco Arboleda, Darío. 2009. “De melancólicos a rumberos... de los Andes a la Costa: la identidad colombiana y la música caribeña". Boletín de Antropología Universidad de Antioquia 23 (40): 102-128.

Bourdieu, Pierre. 1999. “El conocimiento por cuerpos". En Meditaciones pascalinas, 169-214. Barcelona: Anagrama.

Castillo, Luis Carlos. 2007. Etnicidad y nación: el desafío de la diversidad en Colombia. Cali: Universidad del Valle.

Corantioquia (Corporación Autónoma Regional del Centro de Antioquia). 2000. Agenda ambiental urbana: municipio de Girardota. Medellín: Corantioquia.

Corantioquia (Corporación Autónoma Regional del Centro de Antioquia). 2011a. El sainete está corrido: estudio para la postulación como patrimonio cultural inmaterial departamental. Medellín: Corantioquia.

Corantioquia (Corporación Autónoma Regional del Centro de Antioquia). 2011b. Hijos de la rima: una voz bien hablada cuenta la historia del sainete del Consejo Comunitario Afrodescendiente de la vereda de San Andrés. Medellín: Corantioquia.

Correa Bustamante, Carlos Mario. 2002. “De Hatogrande a Girardota". Tesis de grado, Universidad de Antioquia, Medellín, Colombia.

Cuche, Denys. 1996. La notion de culture dans les sciencies sociales. París: Repéres.

Domínguez, María Eugenia. 2011. "Versiones, apropiación e intermusicalidad en el Río de la Plata". Revista Antropoligia em Primeira Mão 126: 3-19.

El balcón. 2014. Identidad y memoria: rastros de la tradición oral en la vereda de San Andrés. Medellín: El balcón. http://otrasletrasvirtual.blogspot.com.co/2014/09/identidad-y-memoriarastros-alegres-de.html

Foronda, Arnobia. 2002. Tradición oral sobre la historia de la vereda de San Andrés Girardota (Antioquia). Girardota, Colombia: Consejo Comunitario de la vereda de San Andrés/Corantioquia.

Gilbert, Shirli. 2005. "Music as Historical Source: Social History and Musical Texts". International Review of the Aesthetics and Sociology of Music 36 (1): 117-134.

Guattari, Félix y Suely Rolnik. 2013. Micropolítica: cartografías del deseo. Buenos Aires: Tinta Limón.

Guerrero, Juliana. 2012. “El género musical en la música popular: algunos problemas para su caracterización". Trans: Revista Transcultural de Música 16: 1-22. http://www.redalyc.org/ pdf/822/82224815008.pdf

Gutiérrez de Pineda, Virginia y Roberto Pineda Giraldo. 1999. Miscegenación y cultura en la Colombia colonial. Bogotá: Universidad de los Andes.

Hernández Salgar, Óscar Andrés. 2014. “Los mitos de la música nacional: poder y emoción en las músicas populares colombianas 1930-1960". Tesis doctoral, Pontificia Universidad Javeriana, Bogotá, Colombia.

Londoño Fernández, María Eugenia. 2009. “Memoria colectiva y músicas locales en una perspectiva de desarrollo humano". Revista de Investigación de la Facultad de Educación y Artes del Conservatorio del Tolima 1 (1): 51-64.

López, Gustavo, Héctor Rendón y Fred Palacio. 2006. Atardecer en San Andrés: música tradicional de Girardota, Antioquia, vereda de San Andrés. Medellín: Universidad de Antioquia.

Menezes Bastos, Rafael José de. 2013. A festa da Jaguatirica: uma partitura critico-interpretativa. Florianópolis: Universidade Federal de Santa Catarina.

Meneses García, Antonio José. 2006. Tierra prolífica, tierra sagrada. Medellín: IDEA. 
Merriam, Alan. 1964. The Anthropology of Music. Evanston: Northwestern University Press.

Merleau-Ponty, Maurice. 1993. Fenomenología de la percepción. Barcelona: Planeta.

Mosquera Mosquera, Juan de Dios. 2001. El cimarronismo. Bogotá: Boletín del Movimiento Nacional Afrocolombiano CimarVrón.

Muñoz, Paloma. 2012. "Violines de negros' del valle interandino del Cauca."Revista A Contratiempo 18: $34-42$.

Ng'weno, Bettina. 2013. “¿Puede la etnicidad reemplazar lo racial? Afrocolombianos, indigenidad y el Estado multicultural en Colombia". Revista Colombiana de Antropología 49 (1): 71-104.

Ochoa, Ana María. 2003. Músicas locales en tiempos de globalización. Buenos Aires: Norma.

Palacio Villa, Andrés. 2014. Con aire de campo. Documental. Medellín: Universidad de Antioquia. https://www.youtube.com/watch?v=yn0a8sUSj7Y

Piedade, Acácio Tadeu. 2007. "Expressão e sentido na música brasileira: retórica e análise musical". Revista eletrônica de musicologia 11: 1-15. http://www.rem.ufpr.br/_REM/REMv11/11/11piedade-retorica.html

Pita Pico, Roger. 2014. La manumisión de esclavos en el proceso de independencia de Colombia: realidades promesas y desilusiones. Bogotá: Juan Luis López.

Rodríguez, Jorge. 1915. Maizopolis: monografías de los distritos antioqueños. Medellín: El Correo Liberal.

Shepherd, Jhon. 1991. Music as Social Text. Cambridge: Polity Press.

Smithsonian Folklife Festival. 2011. "Day Six in Photos", acceso el 10 de octubre de 2017, https:// festival.si.edu/blog/2011/todays-ten-photos-from-77

Wade, Peter. 2002. Música, raza y nación: música tropical en Colombia. Bogotá: Vicepresidencia de la República de Colombia.

Wainer, Jean. 2000. La mundialización de la cultura. Barcelona: Gedisa.

Wabgou, Maguemati. 2012. "Herencia negroafricana en Colombia". Apuntes sobre África y Medio Oriente 9: 99-115.

\section{Cómo citar este artículo:}

Larraín González, América y Pedro José Madrid Garcés. 2017.

“Versiones de lo afro en Antioquia: una aproximación a las estéticas musicales de Girardota". Cuadernos de Música, Artes Visuales y Artes Escénicas 13 (1): 265-280. https://doi. org/10.11144/javeriana.mavae13-1.vaea 